\title{
Classificação do Conteúdo dos Relatórios de Sustentabilidade de Empresas Premiadas por suas Práticas de Responsabilidade Socioambiental
}

\begin{abstract}
Resumo
Dada a importância do relatório de sustentabilidade instrumento de gestão e de divulgação de informações acerca da interação da empresa com o meio em que atua -, o presente estudo tem por objetivo analisar o conteúdo da divulgação de informações acerca das dimensões da sustentabilidade empresarial - econômica, social e ambiental - nos relatórios de empresas premiadas por suas práticas de responsabilidade socioambiental. Trata-se de estudo descritivo, de natureza qualitativa, utilizando-se da pesquisa documental e da Análise de Conteúdo. Os resultados apontam a preponderância da dimensão social, especialmente de âmbito externo, e do disclosure quantitativo não-monetário. Sugerem ainda o efeito da atividade no meio ambiente e a estrutura de propriedade do capital como fatores indicativos dos níveis de evidenciação nos relatórios de sustentabilidade das empresas pesquisadas, dentre aquelas premiadas por suas práticas de responsabilidade socioambiental.
\end{abstract}

Palavras-chave: Evidenciação voluntária; Relatório de sustentabilidade; Dimensões da sustentabilidade; Legitimidade.

\author{
Magdalena Inglês da Costa \\ Graduada em Ciências Contábeis (UFC). \\ Contato: Avenida Sargento Hermínio, \\ 2755, 103-L, Alagadiço, Fortaleza, CE, \\ CEP: 60.350-502. \\ E-mail: magingles@yahoo.com.br \\ Luciana Silva Torres \\ Graduada em Ciências Contábeis (UFC), \\ Bolsista de Pesquisa da Universidade \\ Federal do Ceará (UFC). Contato: Rua \\ Marechal Deodoro, 750, Benfica, \\ Fortaleza, CE, CEP: 60.020-060. \\ E-mail: Iuciana_monit@yahoo.com.br
}

Alessandra Carvalho de Vasconcelos Doutora em Engenharia de Produção (UFSC), Professora Adjunta da Universidade Federal do Ceará (UFC). Contato: Av. da Universidade, 2431, Benfica, Fortaleza, CE, CEP: 60.020-180. E-mail: alegallon@terra.com.br

Márcia Martins Mendes De Luca Doutora em Controladoria e Contabilidade (USP), Professora Associada da Universidade Federal do Ceará (UFC). Contato: Av. da Universidade, 2431, Benfica, Fortaleza, CE, CEP: 60.020-180. E-mail: marciadeluca@ufc.br 


\section{Introdução}

Os incentivos governamentais e as inúmeras premiações que contemplam a Responsabilidade Social Corporativa (RSC) fomentam a transformação do modelo de gestão tradicionalista da empresa, com uma visão mais direcionada para resultados internos e pecuniários, em uma gestão corporativa, que preconiza preceitos da sustentabilidade, observando o impacto da sua atuação na sociedade levando em conta as abordagens econômica, social e ambiental.

A congruência dessas três abordagens deu origem ao conceito do triple bottom line (TBL), ou resultado triplo, também conhecido como o tripé da sustentabilidade empresarial, que considera que a performance de uma entidade deve englobar os aspectos econômicos, sociais e ambientais. Em outras palavras, Vellani e Ribeiro (2009) informam que o conceito TBL reflete sobre a necessidade de as empresas ponderarem em suas decisões estratégicas o bottom line econômico, o bottom line social e o bottom line ambiental. Dessa forma, o TBL, assim como outras diretrizes ou índices - Global Reporting Initiative GRI, Métricas de Sustentabilidade da Instituição dos Engenheiros Químicos da Inglaterra - IChemE e Índice Dow Jones de Sustentabilidade - DJSI (Delai \& Takahashi, 2008) - com foco no ambiente sustentável empresarial adota, de acordo com Wang (2005), a seguinte abordagem do resultado triplo: melhorar o crescimento financeiro reduzindo os impactos ambientais negativos e atendendo às expectativas da sociedade. Segundo o GRI (2009), o conceito de resultado triplo propõe equilíbrio nas complexas relações entre necessidades econômicas, ambientais e sociais que não comprometa o desenvolvimento futuro.

Com base nas considerações do TBL, este trabalho considera que o conceito de sustentabilidade empresarial visa integrar os negócios, a sociedade e os ecossistemas na busca pelo desenvolvimento sustentável, conceito compartilhado com diversos autores, dentre os quais estão Almeida (2002) e Vellani e Ribeiro (2009). Seguindo perspectiva semelhante, Ferreira (2011) elucida que a sustentabilidade empresarial deve refletir um conjunto de valores, princípios e processos que uma entidade deve perseguir com o intuito de criar valor nas dimensões econômica, social e ambiental, minimizando qualquer dano resultante de sua atuação no mercado.

No que se referem às dimensões da sustentabilidade empresarial, Almeida (2002) adverte que a dimensão econômica inclui não só a economia formal, mas também as atividades informais que proveem serviços para os indivíduos e aumentam, assim, a renda monetária e o padrão de vida dos indivíduos. Cabe lembrar, conforme esclarecem Delai e Takahashi (2008, p. 35), que a dimensão econômica "está relacionada com a saúde financeira da organização no curto e longo prazo" e ao relacionamento que esta mantém com seus acionistas e investidores. No que se refere à dimensão ambiental (ou ecológica), os autores indagam que ela estimula organizações a considerarem o impacto de suas atividades sobre o meio ambiente e contribui para a integração da administração ambiental na rotina de trabalho. Assim como em Prescott-Allen (1997, p. 7), considera-se nesta pesquisa que a dimensão ambiental da sustentabilidade empresarial lida com a "condição na qual o ecossistema mantém sua diversidade e qualidade, sua capacidade de suportar a vida e seu potencial de adaptar às mudanças provendo futuras opções." Quanto à dimensão social, Almeida (2002) explica que ela está relacionada às qualidades dos seres humanos, abrangendo tanto o ambiente interno da empresa quanto o externo. Conforme adotado no trabalho de Delai e Takahashi (2008), a dimensão social neste estudo leva em conta o relacionamento da empresa com todas as suas partes interessadas (stakeholders): funcionários, sociedade, governo, consumidores, fornecedores, dentre outros.

Além de fatores de pressão - positiva e negativa - relacionados às abordagens econômica, social e ambiental, a demanda de alguns agentes é fundamental no incentivo dado às empresas para evidenciar voluntariamente informações socioambientais (Ribeiro \& Van Bellen, 2008) a fim de obter reconhecimento da sociedade. De acordo com Gray e Bebbington (2001), dentre os agentes de influência relacionados à iniciativas voluntárias na evidenciação socioambiental de uma empresa, destacam-se: Organização das Nações Unidas (ONU), GRI, comitês de desenvolvimento, associações industriais, eco-labelling (proteção de efeito semelhante ao das barreiras técnicas ao comércio) e prêmios socioambientais (fator considerado na pesquisa). 
Os prêmios socioambientais representam o reconhecimento da sociedade às empresas social e ambientalmente responsáveis. Esse reconhecimento está relacionado à Teoria da Legitimidade, segundo a qual as empresas buscam mecanismos para se legitimar perante a sociedade (Nascimento, Santos, Salotti, \& Múrcia, 2009). Nesse caso, as empresas se esforçam por ser percebidas pela sociedade como responsáveis, e, assim, ficam estimuladas a continuar operando de forma eficiente no meio em que estão inseridas. Segundo Deegan (2005), a teoria da legitimidade tem ampla aplicação nas diferentes estratégias corporativas, em particular naquelas que envolvem o disclosure de informação da organização.

Dessa forma, para se alcançar a legitimidade das práticas de responsabilidade social e ambiental adotadas pelas empresas, torna-se imprescindível a publicação de informações por meio de instrumentos eficazes e de boa qualidade. Para Vanstraelen, Zazerski e Robb (2003), o processo decisório deve ter como apoio um conjunto de informações que retratem a real situação da empresa. Desse modo, a discussão acerca da extensão das informações voluntárias, sobretudo de natureza socioambiental, gera dúvidas sobre o que e quanto deve ser divulgado, devido à inexistência de parâmetros.

Ante o exposto, o presente estudo procura investigar a associação de duas temáticas - a evidenciação voluntária e a sustentabilidade empresarial - pela ótica da Teoria da Legitimidade, de maneira a responder ao seguinte questionamento: Qual o conteúdo das informações acerca das dimensões da sustentabilidade empresarial - econômica, social e ambiental - nos relatórios de sustentabilidade de empresas premiadas por suas práticas de responsabilidade socioambiental? Para responder a esse questionamento, têm-se como objetivo geral analisar o conteúdo da divulgação de informações acerca das dimensões da sustentabilidade empresarial - econômica, social e ambiental - nos relatórios de sustentabilidade de empresas premiadas por suas práticas de responsabilidade socioambiental. Com vistas ao alcance desse objetivo, foram delineados os seguintes objetivos específicos: 1) examinar o nível de evidenciação sobre as dimensões da sustentabilidade e tipos de disclosure adotados pelas empresas pesquisadas; e 2) identificar possíveis fatores indicativos dos níveis de evidenciação acerca das dimensões da sustentabilidade nos relatórios de sustentabilidade das empresas pesquisadas.

Foi procedida a análise de conteúdo dos relatórios de sustentabilidade de 2007, 2008 e 2009 das empresas da amostra, a qual considerou o número de sentenças como unidade de análise, contemplando dois campos de observação: (i) as dimensões da sustentabilidade empresarial - econômica, social (dividida em interna e externa) e ambiental; e (ii) o tipo de disclosure - tipo 1: sentença declarativa; tipo 2: sentença quantitativa não-monetária; tipo 3: sentença quantitativa monetária.

A amostra reuniu as empresas premiadas no Guia Exame de Sustentabilidade, da Editora Abril (2009), e as vencedoras do Prêmio ECO, da AMCHAM e do Valor Econômico (2007, 2008 e 2009). Essas duas premiações consideram como critério de avaliação as principais referências de indicadores de sustentabilidade empresarial no Brasil e no mundo.

Acredita-se que os achados da presente pesquisa, referentes ao conteúdo da divulgação de informações sobre as dimensões da sustentabilidade nos relatórios de empresas socialmente responsáveis proeminentes dos prêmios recebidos poderão servir de parâmetro para empresas que não fazem parte desse universo, mas que também buscam a aprovação da sociedade.

A despeito de inúmeras pesquisas relacionadas aos temas divulgação voluntária e sustentabilidade empresarial, evidenciam-se lacunas nas pesquisas empíricas que se propõem a conectar os dois temas com empresas premiadas por suas práticas de responsabilidade socioambiental. Assim, justifica-se a escolha da amostra representada por empresas premiadas, que receberam um reconhecimento público em relação à maturidade, ao desenvolvimento e integração da sua sustentabilidade empresarial, o que permite uma avaliação mais completa dos objetivos propostos no presente estudo.

Considerando esse contexto, o tema deste estudo encontra relevância justamente nas lacunas observadas, propondo compor uma visão sobre a classificação do conteúdo dos relatórios de sustentabilidade de empresas premiadas por suas práticas de responsabilidade socioambiental, independente da sua estrutura de propriedade do capital, aberto ou fechado, aspecto que também representa um diferencial da presente pesquisa. 
Com a análise de empresas premiadas pelo Guia Exame de Sustentabilidade e vencedoras do Prêmio ECO, procurou-se eliminar a possibilidade de o conteúdo das informações acerca das dimensões da sustentabilidade empresarial ser inadequado para os objetivos propostos no estudo. Portanto, cabe reafirmar que o fato de as empresas terem sido premiadas, o que supõe uma estratégia ou ação bem sucedida, qualificou-as para a presente pesquisa.

\section{Divulgação de informações socioambientais - abordagem teórica e estudos anteriores}

A teoria da legitimidade é considerada uma das teorias dominantes na investigação sobre a divulgação de informações socioambientais (Deegan, 2002). Legitimidade é a percepção ou suposição de que as ações de uma entidade são desejáveis, apropriadas ou adequadas em um sistema socialmente construído de normas, valores e crenças (Suchman, 1995). Deegan (2005) afirma que os defensores da teoria da legimitadade abordam a necessidade das organizacões de atender às expectativas da sociedade. Para tanto, torna-se necessário que as empresas divulguem seus projetos e respectivos resultados.

Segundo Guthrie e Parker (1989), os relatórios contábeis representam uma ferramenta para a construção, manutenção e legitimação dos acordos (explícitos ou implícitos) entre as organizações e a sociedade e contribuem para o alcance dos interesses de ambas as partes. Ou seja, a legitimidade é influenciada pela divulgação de informações sobre o desempenho da organização, e não simplesmente pelas suas realizações. Ressalta-se, no entanto, a necessidade de elevação do nível de qualidade da informação divulgada (Adams, Hill \& Roberts, 1998).

Nessa perspectiva, Cho e Patten (2007) apontam pontos importantes para os relatórios ambientais, como: informações e preocupações com a política ambiental, debates sobre o controle de poluição, regulamentações ambientais, divulgação do capital, dos investimentos em controles de poluição ou redução de emissões e dos projetados para investimentos futuros. Adams (2004) comenta que foi em meados dos anos 1980 que houve um incremento significativo da evidenciação socioambiental por parte das empresas e daí deu-se início, na academia, a uma linha de pesquisa que tem como principal foco o estudo do que e de como as empresas fazem este tipo de evidenciação.

Gray, Kouhy e Lavers (1995) entendem que a teoria da legitimidade é a que melhor interpreta os fundamentos para a compreensão de como, e por que, os gestores utilizam o disclosure na perspectiva de beneficiarem a organização, especialmente quanto aos elementos relacionados à sustentabilidade.

Autores como Brown e Deegan (1998) e Deegan, Rankin e Tobin (2002) enfatizam que não se pode deixar de ressaltar o que mostra a teoria da legitimidade, no que diz respeito à motivação e incentivos que as empresas têm para fazer disclosure socioambiental. Mattila (2009) complementa a afirmação desses autores ao informar que o proporcionou maior atenção à responsabilidade socioambiental nos últimos anos foi um melhor entendimento de seus benefícios potenciais para a competitividade das empresas, por meio, principalmente, da promoção da imagem corporativa.

Diversos autores contribuíram para o aumento de estudos que analisam a informação divulgada pelas empresas, considerando que estas têm como principal motivação a preocupação em legitimar suas atividades (Gray, Kouhy \& Lavers, 1995; Guthrie \& Parker, 1989; Branco, Eugênio \& Ribeiro, 2008; Aerts \& Cormier, 2009). Branco, Eugénio e Ribeiro (2008) investigaram as mudanças nos níveis de disclosure ambiental voluntário de duas empresas em Portugal, em resposta a manifestações da sociedade contrárias as suas atividades de natureza poluente. Os autores sugerem que uma das empresas utilizou o disclosure de forma a minimizar a polêmica, "gerenciando" a sua legitimidade, enquanto a outra abordou diretamente a questão, apresentando detalhes do problema em seu relatório. Aerts e Cormier (2009) reportaram que os resultados divulgados pelas empresas dos Estados Unidos e do Canadá em seus relatórios de sustentabilidade produzem impacto direto sobre a imagem institucional das empresas pesquisadas.

Como mencionam Anderson e Frankle (1980), a divulgação pública de um conjunto de informações sobre o envolvimento da empresa com a comunidade, funcionários, meio ambiente e benefícios dos produtos ofertados é conhecida como disclosure social. 
Entre os estudos internacionais que investigaram a problemática relacionada a essa pesquisa destacam-se os de Gray, Kouhy e Lavers (1995), Al-Tuwaijri,Christensen e Hughes II (2004), Kuasirikun e Sherer (2004), Cho e Patten (2007) e Clarkson, Jacobsen e Batcheller (2007), que exploraram a temática sob diferentes abordagens e contextos mas não apresentaram uma abordagem diferenciada, direcionada para os aspectos de caráter eminentemente socioambientais como a que se apresenta. Além disso, cabe enaltecer a análise proposta nesse estudo da identificação de possíveis fatores indicativos dos níveis de evidenciação sobre as dimensões da sustentabilidade nos relatórios das empresas pesquisadas, que mesmo sem o uso de técnicas estatísticas inferenciais, releva pontos importantes para discussões acadêmicas futuras com abordagem quantitativa.

A pesquisa de Gray, Kouhy e Lavers (1995) buscou descrever as práticas de evidenciação em relatórios ambientais e sociais de empresas do Reino Unido, de 1979 a 1991, e revelou que houve uma mudança significativa no comportamento da divulgação social e ambiental durante o período analisado.

O estudo de Al-Tuwaijri, Christensen e Hughes II (2004) faz uma análise da interrelação existente entre evidenciação ambiental, performance ambiental e performance econômica, utilizando uma abordagem de equação simultânea. Os autores constataram que uma boa performance ambiental é significativamente associada a uma boa performance econômica, e, também, associada com uma evidenciação ambiental mais extensiva quantitativamente de medidas e ocorrências específicas de poluição.

Mais especificamente sobre as características da evidenciação ambiental, o estudo de Kuasirikun e Sherer (2004) analisou empresas da Tailândia e demonstrou que a maioria das informações sobre o meio ambiente é divulgada no Relatório da Administração, de forma declarativa e apresentada por meio de notícias positivas.

Os resultados da pesquisa de Cho e Patten (2007) - que teve como objetivo comprovar o papel da teoria da legitimidade na evidenciação das informações ambientais - apontam uma variação na utilização da evidenciação por diferentes grupos empresariais. Os resultados generalizados do estudo dão um suporte adicional ao argumento de que as firmas utilizam as evidenciações ambientais como ferramenta de atingir a legitimidade.

Clarkson et al. (2007) buscaram revisar a relação entre evidenciação e performance ambiental utilizando os preceitos das teorias econômica e social-política de evidenciação voluntárias, tendo como base uma amostra de 191 empresas dos cinco setores mais poluentes dos Estados Unidos, e constataram a existência de uma associação positiva entre performance ambiental e o nível de evidenciação ambiental discricionária.

Diante da importância do tema, a divulgação de informações voluntárias sobre as práticas de responsabilidade socioambiental por empresas brasileiras gerou uma série de pesquisas nos últimos anos, muitas das quais apresentaram resultados contraditórios e, algumas vezes, inconsistentes.

Dentre os estudos nacionais que abordaram a temática, destacam-se os de Milani Filho (2008), Cunha e Ribeiro (2008), Rezende, Junqueira e Medeiros (2008), Rover e Murcia (2010), Teixeira e Nossa (2010) e Moura, Nascimento e De Luca (2010).

Milani Filho (2008) investigou se as empresas que se declaram socialmente responsáveis divulgam informações financeiras específicas sobre os recursos gastos em benefício público (investimento social privado) e se há diferença significativa entre os gastos nas empresas cujos produtos são associados a externalidades negativas e os das organizações participantes do Îndice de Sustentabilidade Empresarial (ISE) da BM\&FBovespa. Os resultados apontaram que nem todas as organizações que declaram realizar investimentos sociais evidenciam tal fato. Foi constatado que $11,8 \%$ das empresas integrantes da carteira do ISE e 72,2\% das empresas vinculadas a externalidades negativas não divulgam informações sobre os gastos sociais, gerando dúvidas na comunidade sobre a realização ou a dimensão dos investimentos.

Após investigar os incentivos das companhias com ações negociadas na BM\&Bovespa para divulgação voluntária de informações de natureza social, abrangendo o período de 2004 a 2006, Cunha e Ribeiro (2008) concluíram que o grau de espontaneidade depende do nível de governança corporativa, do desempenho e do tamanho da empresa, assim como de experiências anteriores nesse particular. 
Rezende, Junqueira e Medeiros (2008) analisaram as práticas de responsabilidade social de empresas brasileiras premiadas no Guia Exame de Sustentabilidade de 2007, constatando que em todas elas há uma responsabilidade social orientada do âmbito interno para o externo, materializada pela preocupação de desenvolver em seus funcionários uma cultura voltada para trabalhos voluntários e ambientais.

Rover e Murcia (2010) investigaram se o nível de disclosure voluntário econômico e socioambiental influencia o custo de capital próprio de empresas brasileiras. Os resultados da pesquisa indicam que o nível de disclosure voluntário influencia o custo de capital das empresas; porém, não foi aceita a hipótese de que quanto maior for o disclosure voluntário, menor será o custo de capital.

O estudo de Teixeira e Nossa (2010), que investigou se a forma de financiamento das empresas é afetada pela sua participação no índice de sustentabilidade empresarial (ISE) e se há relação entre o ISE e o risco (sistemático) de mercado, evidenciou que as empresas que sinalizaram responsabilidade social corporativa (RSC) tiveram uma relação negativa com o endividamento e o risco, diferentemente do que ocorreu com as demais.

Moura, Nascimento e De Luca (2010) investigaram a evidenciação voluntária de informações sociais de empresas das regiões Norte, Nordeste, Centro-Oeste e Sudeste, segundo os indicadores de RSC contidos no Guia da ONU, podendo constatar que os indicadores mais evidenciados são aqueles exigidos pela legislação vigente no país - contrariando a ideia da evidenciação social voluntária - e que os menos evidenciados são os de caráter não financeiro.

Becchetti, Di Giacomo e Pinnacchio (2005) ressaltam que as diferenças de resultados encontradas em estudos dessa temática não necessariamente refletem erros, mas implicam diferenças nas perspectivas (períodos de observação, empresas selecionadas, medidas de desempenho e abordagens metodológicas). Embora alguns estudos suportem a visão de que determinadas divulgações são feitas pelas empresas para aumentar a sua legitimidade, a presente pesquisa se justifica na medida em que procura analisar o conteúdo da divulgação de informações sobre as dimensões da sustentabilidade empresarial (econômica, social e ambiental) nos relatórios de sustentabilidade, na perspectiva de empresas premiadas por suas práticas de responsabilidade socioambiental, consideradas neste estudo a título de benchmark.

Destaca-se ainda a escolha de empresas premiadas no contexto da teoria da legitimidade, que atribui grande importância à percepção da sociedade sobre as empresas. Essa distinção pela sociedade pode ser traduzida em prêmios que, de acordo com Voss, Pfitscher e Cruz (2010, p. 4), se propõem, de forma comum, reconhecer as empresas que possuem "uma maior transparência e participação com a comunidade e meio ambiente na visão de encontrar uma situação que seja melhor para todos: governo, sociedade, empresários, cidadãos, natureza e para o futuro".

\section{Procedimentos metodológicos}

Levando-se em conta seu objetivo, a pesquisa do tipo descritiva, com abordagem qualitativa, adota os procedimentos bibliográfico e documental.

Para responder à questão de pesquisa, a seleção das empresas que integram a amostra se deu a partir da população de empresas premiadas no Guia Exame de Sustentabilidade, da Editora Abril, edição 2009, e vencedoras do Prêmio ECO, da AMCHAM e do Valor Econômico, nos anos 2007, 2008 e 2009 - premiações que consideram como critério de avaliação das empresas as principais referências de indicadores de sustentabilidade empresarial no Brasil e no mundo -, conforme exibe a Figura 1. 
Guia Exame de Sustentabilidade (Editora Abril)

Empresas vencedoras (2009)

AES Tietê S.A., Alcoa Alumínio S.A., Amanco Serviços e Participações Ltda, Anglo American Brasil Ltda., Banco Bradesco S.A., BRF - Brasil Foods S.A., Bunge Alimentos S.A., Companhia Energética do Ceará - Coelce, CPFL Energia S.A., EDP - Energias do Brasil S.A., Fibria Celulose S.A., Itaú Unibanco S.A., Masisa do Brasil Ltda., Natura Cosméticos S.A., Philips do Brasil Ltda., Promon S.A., Serasa S.A., Suzano Papel e Celulose S.A., Tetra Pak Ltda. e Walmart Brasil Ltda.

\section{Critérios de análise}

- Critérios ambientais utilizados para todas as etapas do processo produtivo

- Empresas que possuem projetos com o desenvolvimento de metas para redução de consumo de água

- Publicação dos relatórios de sustentabilidade

- Estabelecimento de metas de melhoria de desempenho e prestação de contas dos compromissos assumidos no ano anterior

- Investimentos em sustentabilidade para enfrentamento da última crise mundial

Prêmio ECO (AMCHAM e Valor Econômico)

Empresas vencedoras (2007, 2008 e 2009)

- Categorias:

- Sustentabilidade no modelo de negócios

ABN AMRO Real S.A., Banco Santander Brasil S.A., Bradesco Capitalização S.A., BrasilPrev Seguros e Previdência S.A., Carbocloro S.A. Indústrias Químicas, Companhia de Desenvolvimento dos Vales do São Francisco e do Parnaíba - CODEVASF, Eco Negócios Sustentáveis Ltda., E-TAB Tecnologia e Gestão Ltda., Intelcav Cartões Ltda., Itaipu Binacional, Microsoft Brasil e Multiplus Comercial de Alimentos Ltda.

Categorias de premiação e Critérios de análise

- Sustentabilidade em novos projetos

- Sustentabilidade em processos

- Sustentabilidade em produtos

- Critérios de análise:

- Relevância para o negócio

- As contribuições de melhoria no desempenho da empresa

- Resultados sociais e ambientais obtidos com a inovação

- Gestão da inovação relatada

- Possibilidade de disseminação ou replicação

- Qualidade das informações prestadas

- Grau de inovação

Figura 1. População da pesquisa

Fonte: Dados da pesquisa.

Conforme apresentado na Figura 1, a população da pesquisa compreende 32 empresas, sendo 20 vencedoras do Guia Exame de Sustentabilidade, da Editora Abril (2009), e 12 vencedoras do Prêmio ECO, da AMCHAM e do Valor Econômico (2007, 2008 ou 2009).

A Figura 2 delimita a amostra da pesquisa, a partir do critério de publicação dos relatórios de sustentabilidade dos anos 2007, 2008 e/ou 2009, nos sites das empresas da amostra.

\begin{tabular}{|llllc|}
\hline \multicolumn{1}{c}{ Empresa } & \multicolumn{3}{c|}{$\begin{array}{c}\text { Relatório de Sustentabilidade (RS) } \\
\text { Exercício/Modelo }\end{array}$} \\
\cline { 2 - 6 } & 2007 & 2008 & 2009 & Modelo \\
\hline ABN AMRO Real S.A. & Não & Não & Não & - \\
\hline AES Tietê S.A. & Sim & Sim & Sim & GRI \\
\hline Alcoa Alumínio S.A. & Não & Sim & Sim & GRI \\
\hline Amanco Serviços e Participações Ltda. & Não & Sim & Sim & GRI \\
\hline Anglo American Brasil Ltda. & Sim & Sim & Sim & GRI \\
\hline Banco Santander Brasil S.A. & Sim & Sim & Sim & GRI \\
\hline Banco Bradesco S.A. & Sim & Sim & Sim & GRI \\
\hline Bradesco Capitalização S.A. & Não & Não & Não & - \\
\hline BrasilPrev Seguros e Previdência S.A. & Não & Sim & Sim & Próprio \\
\hline BRF - Brasil Foods S.A. & Sim & Sim & Sim & GRI \\
\hline Bunge Alimentos S.A. & Sim & Sim & Sim & GRI \\
\hline Carbocloro S.A. Indústrias Químicas & Não & Sim & Não & GRI \\
\hline
\end{tabular}




\begin{tabular}{|c|c|c|c|c|}
\hline \multirow[t]{2}{*}{ Empresa } & \multicolumn{4}{|c|}{$\begin{array}{l}\text { Relatório de Sustentabilidade (RS) } \\
\text { Exercício/Modelo }\end{array}$} \\
\hline & 2007 & 2008 & 2009 & Modelo \\
\hline Companhia Energética do Ceará - Coelce & Sim & Sim & Sim & GRI \\
\hline $\begin{array}{l}\text { Companhia de Desenvolvimento dos Vales do São Francisco e do } \\
\text { Parnaíba - Codevasf }\end{array}$ & Não & Não & Não & - \\
\hline CPFL Energia S.A. & $\operatorname{Sim}$ & Sim & Sim & GRI \\
\hline Eco Negócios Sustentáveis Ltda. & Não & Não & Não & - \\
\hline EDP - Energias do Brasil S.A. & Sim & Sim & Sim & GRI \\
\hline E-TAB Tecnologia e Gestão Ltda. & Não & Não & Não & - \\
\hline Fibria Celulose S.A. & Sim & Sim & Sim & GRI \\
\hline Intelcav Cartões Ltda. & Não & Não & Não & - \\
\hline Itaipu Binacional & $\operatorname{Sim}$ & Sim & Sim & GRI \\
\hline Itaú Unibanco S.A. & $\operatorname{Sim}$ & Sim & Sim & GRI \\
\hline Masisa do Brasil Ltda. & Sim & Sim & Sim & Próprio \\
\hline Microsoft Brasil & Sim & Sim & Sim & Próprio \\
\hline Multiplus Comércio de Alimentos Ltda. & Não & Não & Não & - \\
\hline Natura Cosméticos S.A. & Não & Sim & Sim & GRI \\
\hline Philips do Brasil Ltda. & Não & Sim & Sim & GRI \\
\hline Promon S.A. & Sim & $\operatorname{Sim}$ & Sim & Próprio \\
\hline Serasa S.A. & $\operatorname{Sim}$ & Não & Sim & GRI \\
\hline Suzano Papel e Celulose S.A. & Sim & Sim & Sim & GRI \\
\hline Tetra Pak Ltda. & Sim & Sim & Não & GRI \\
\hline Walmart Brasil Ltda. & Sim & Sim & Sim & GRI \\
\hline
\end{tabular}

Figura 2. Amostra da pesquisa: empresas que publicaram relatório de sustentabilidade no período de 2007 a 2009 Fonte: Dados da pesquisa.

Na Figura 2, verifica-se que 25 empresas (ou 78,1\% da população) elaboraram e disponibilizaram seus relatórios de sustentabilidade em pelo menos um dos três anos delimitados pela pesquisa, sendo 19 em 2007, 24 em 2008 e 23 em 2009. Observa-se que a maioria das empresas adotou o modelo da Global Reporting Initiative (GRI) - organização internacional que reúne representantes de governos, empresas e entidades civis - na elaboração dos relatórios de sustentabilidade.

Após a definição do universo amostral do estudo, partiu-se para a análise do conteúdo dos relatórios de sustentabilidade das empresas referentes aos exercícios de 2007, 2008 e 2009. No que tange à análise de conteúdo, foram observadas as três fases do método, conforme Bardin (2004): (1) pré-análise; (2) exploração do material, que, nesse caso, compreendeu os relatórios de sustentabilidade; e (3) tratamento dos resultados, inferência e interpretação.

Nesta pesquisa optou-se pela utilização de sentenças (frases), como unidades de análise, para a codificação e para a quantificação da evidenciação. Para a realização da análise de conteúdo, procedeu-se à contagem de sentenças relacionadas aos campos de observação - dimensões da sustentabilidade empresarial: econômica, social interna, social externa e ambiental; e aos tipos de disclosure: tipo 1 - sentença declarativa, tipo 2 - sentença quantitativa não-monetária e tipo 3 - sentença quantitativa monetária - nos relatórios de sustentabilidade, do período de 2007 a 2009, das empresas premiadas no Guia Exame de Sustentabilidade, da Editora Abril (2009), e das vencedoras do Prêmio ECO, da AMCHAM e do Valor Econômico (2007, 2008 e 2009). 
A análise de conteúdo aplicada se inicia de forma qualitativa, por meio de leitura e interpretação das mensagens dos textos, e prossegue de forma quantitativa, a partir da codificação e quantificação (contagem da frequência) de cada elemento de evidenciação observado. Os tipos de evidenciação considerados para este estudo, em consonância com a proposta de Nossa (2002), são: tipo 1) evidenciação declarativa - quando a informação qualitativa é descrita e expressa em termos exclusivamente descritivos; tipo 2) evidenciação quantitativa não-monetária - quando a informação quantitativa é descrita e expressa em números de natureza não financeira; e tipo 3) evidenciação quantitativa monetária - quando a informação quantitativa é descrita e expressa em números de natureza financeira.

A Figura 3 apresenta alguns exemplos de sentenças divulgadas nos relatórios de sustentabilidade (RS) analisados, por dimensão da sustentabilidade e por tipo de disclosure.

\begin{tabular}{|c|c|c|}
\hline $\begin{array}{l}\text { Dimensão da } \\
\text { sustentabilidade }\end{array}$ & $\begin{array}{l}\text { Tipo de } \\
\text { disclosure }\end{array}$ & Sentença \\
\hline \multirow{3}{*}{ Econômica } & 1 & $\begin{array}{l}\text { É a instituição líder dos conglomerados financeiro e econômico-financeiro perante o } \\
\text { Banco Central (Santander, RS 2008) }\end{array}$ \\
\hline & 2 & $\begin{array}{l}\text { Possui } 60 \text { unidades industriais no Brasil e três no exterior (Argentina, Inglaterra e } \\
\text { Holanda), exporta para mais de } 110 \text { países e seu portfólio reúne mais de } 3.000 \text { itens } \\
\text { (BRF - Brasil Foods, RS 2009) }\end{array}$ \\
\hline & 3 & $\begin{array}{l}\text { As vendas na região alcançaram o recorde de US\$2,9 bilhões, gerando lucro líquido } \\
\text { de US } \$ 475 \text { milhões (Alcoa, RS 2008) }\end{array}$ \\
\hline \multirow{3}{*}{ Social Interna } & 1 & $\begin{array}{l}\text { Figura entre as melhores empresas para se trabalhar no ranking organizado pelas } \\
\text { revistas Exame e Você S/A (Coelce, RS 2009) }\end{array}$ \\
\hline & 2 & $\begin{array}{l}\text { Registrou } 1.502 \text { participações de colaboradores em cursos, totalizando } 20.428 \\
\text { homens-hora de treinamento (AES Tietê, RS 2007) }\end{array}$ \\
\hline & 3 & $\begin{array}{l}\text { Distribuiu com seus colaboradores, por meio de três programas, cerca de } \mathrm{R} \$ 35,5 \\
\text { milhões (Bunge Alimentos, RS 2007) }\end{array}$ \\
\hline \multirow{3}{*}{ Social Externa } & 1 & $\begin{array}{l}\text { Suas atividades movimentam uma grande cadeia produtiva, que alavanca o } \\
\text { desenvolvimento socioeconômico das regiões onde atua (Fibria, RS 2007) }\end{array}$ \\
\hline & 2 & $\begin{array}{l}\text { A CPFL Leste Paulista doou } 143 \text { geladeiras de alta eficiência energética e } 4.950 \\
\text { lâmpadas, enquanto a CPFL Mococa doou } 120 \text { geladeiras e substituiu } 3.180 \text { lâmpadas } \\
\text { (CPFL, RS 2007) }\end{array}$ \\
\hline & 3 & $\begin{array}{l}\text { Programas socioculturais apoiados e promovidos pela empresa, com foco em } \\
\text { iniciativas nas áreas de educação e desenvolvimento local, receberam investimento } \\
\text { de } R \$ 8,5 \text { milhões (EDP, RS 2009) }\end{array}$ \\
\hline \multirow{3}{*}{ Ambiental } & 1 & $\begin{array}{l}\text { A estrutura estabelecida possibilita que o compromisso institucional vá além das } \\
\text { medidas ambientais legais, promovendo formas de ampliar sua participação na } \\
\text { manutenção e na preservação da biodiversidade local (Anglo American, RS 2008) }\end{array}$ \\
\hline & 2 & $\begin{array}{l}\text { Redução do consumo de água ( } 8,9 \% \text { ) e energia }(16,9 \%) \text { nas operações industriais, por } \\
\text { unidade faturada (Natura, RS 2008) }\end{array}$ \\
\hline & 3 & Mais de $\mathrm{R} \$ 2,5$ milhões investidos nas unidades florestais (Suzano, RS 2008) \\
\hline
\end{tabular}

Figura 3. Exemplificação de sentenças divulgadas nos RS das empresas pesquisadas Fonte: Elaborado pelos autores.

Dessa forma, os tipos de evidenciação mutuamente excludentes e exaustivos considerados para este estudo são: declarativo, quantitativo monetário e quantitativo não-monetário, referentes às dimensões da sustentabilidade empresarial, encontrados nos relatórios de sustentabilidade das empresas pesquisadas.

Cabe destacar que uma das limitações do estudo diz respeito à análise dos níveis de evidenciação das informações, a qual tomou como base um instrumento voltado para avaliar apenas a quantidade referente ao tipo de informação, e não a sua qualidade. 


\section{Resultados da pesquisa}

\subsection{Caracterização das empresas}

A Figura 4 apresenta a distribuição das 25 empresas participantes da amostra - vencedoras do Guia Exame de Sustentabilidade, da Editora Abril (2009), e vencedoras do Prêmio ECO, da AMCHAM e do Valor Econômico (2007, 2008 ou 2009) - por de setor de atividade, efeito da atividade no meio ambiente, porte, estrutura de propriedade do capital e segmento de listagem da BM\&FBovespa. Para a definição do setor e da natureza de atividade das empresas, foi utilizado o Anexo VIII da Lei no 10.165/2000, que trata da Política Nacional do Meio Ambiente. Quanto ao porte, com base na receita bruta das empresas no exercício findo em 31/12/2009, considerou-se a classificação da referida lei, cujo artigo 17-D, informa que se considera empresa de médio porte a pessoa jurídica com receita bruta anual superior a $R \$ 1.200 .000,00$ e não superior a $R \$ 12.000 .000,00$, e empresa de grande porte a pessoa jurídica com receita bruta anual superior a $\mathrm{R} \$ 12.000 .000,00$.

\begin{tabular}{|c|c|c|c|c|c|}
\hline Empresa & Setor de atividade & $\begin{array}{c}\text { Efeito da } \\
\text { atividade no } \\
\text { meio ambiente }\end{array}$ & Porte & $\begin{array}{c}\text { Estrutura de } \\
\text { propriedade } \\
\text { do capital }\end{array}$ & $\begin{array}{l}\text { Segmento de } \\
\text { listagem da } \\
\text { BM\&FBovespa }\end{array}$ \\
\hline AES Tietê S.A. & Energia & Poluente & Grande & Aberto & - \\
\hline Alcoa Alumínio S.A. & Siderurgia/metalurgia & Poluente & Grande & Fechado & - \\
\hline $\begin{array}{l}\text { Amanco Serviços e } \\
\text { Participações Ltda. }\end{array}$ & $\begin{array}{l}\text { Indústria da } \\
\text { construção }\end{array}$ & Poluente & Grande & Fechado & - \\
\hline Anglo American Brasil Ltda. & Mineração & Poluente & Grande & Fechado & - \\
\hline Banco Santander Brasil S.A. & Finanças & Não poluente & Grande & Aberto & Nível 2 \\
\hline Banco Bradesco S.A. & Finanças & Não poluente & Grande & Aberto & Nível 1 \\
\hline $\begin{array}{l}\text { BrasilPrev Seguros e } \\
\text { Previdência S.A. }\end{array}$ & Seguros/previdência & Não poluente & Médio & Fechado & - \\
\hline BRF - Brasil Foods S.A. & Bens de consumo & Poluente & Grande & Aberto & Novo Mercado \\
\hline Bunge Alimentos S.A. & Bens de consumo & Poluente & Grande & Fechado & - \\
\hline $\begin{array}{l}\text { Carbocloro S.A. Indústrias } \\
\text { Químicas }\end{array}$ & Petroquímica & Poluente & Médio & Fechado & - \\
\hline $\begin{array}{l}\text { Companhia Energética do } \\
\text { Ceará - Coelce }\end{array}$ & Energia & Poluente & Grande & Aberto & - \\
\hline CPFL Energia S.A. & Energia & Poluente & Grande & Aberto & Novo Mercado \\
\hline EDP - Energias do Brasil S.A. & Energia & Poluente & Grande & Aberto & Novo Mercado \\
\hline Fibria Celulose S.A. & Papel e celulose & Poluente & Grande & Aberto & Novo Mercado \\
\hline Itaipu Binacional & Energia & Poluente & Grande & Fechado & - \\
\hline Itaú Unibanco S.A. & Finanças & Não poluente & Grande & Aberto & Nível 1 \\
\hline Masisa do Brasil Ltda. & Madeira & Poluente & Grande & Fechado & - \\
\hline Microsoft Brasil & Informática & Não poluente & Grande & Fechado & - \\
\hline Natura Cosméticos S.A. & Bens de consumo & Poluente & Grande & Aberto & Novo Mercado \\
\hline Philips do Brasil Ltda. & Eletroeletrônico & Poluente & Grande & Fechado & - \\
\hline Promon S.A. & Serviços & Não poluente & Grande & Fechado & - \\
\hline Serasa S.A. & Serviços & Não poluente & Grande & Fechado & - \\
\hline Suzano Papel e Celulose S.A. & Papel e celulose & Poluente & Grande & Aberto & Nível 1 \\
\hline Tetra Pak Ltda. & Embalagens & Poluente & Grande & Fechado & - \\
\hline Walmart Brasil Ltda. & Comércio Varejista & Não poluente & Grande & Fechado & - \\
\hline
\end{tabular}

Figura 4. Caracterização das empresas da amostra da pesquisa

Fonte: Dados da pesquisa. 
Com base nos dados do Quadro 4, verifica-se uma predominância de empresas dos setores energia (5), finanças (3) e bens de consumo (3). Quanto ao efeito no meio ambiente, nota-se que 17 empresas (68\%) enquadram-se como poluentes. Verifica-se ainda que apesar da quase unanimidade de empresas de grande porte (23), apenas 11 delas possuem capital aberto, nove das quais são listadas nos Níveis Diferenciados de Governança Corporativa da BM\&FBovespa (Nível 1, Nível 2 ou Novo Mercado). Apesar da pequena proporção de empresas de capital aberto em relação ao universo amostral estudado, percebe-se que não apenas as listadas em bolsa - a fim de atrair investidores, dentre outros objetivos - mas também as de capital fechado estão assumindo a realização, o controle e a divulgação de práticas de responsabilidade socioambiental.

\subsection{Níveis de evidenciação sobre as dimensões da sustentabilidade empresarial e tipos de disclosure adotados pelas empresas pesquisadas}

A Tabela 1 apresenta a quantidade de sentenças evidenciadas sobre as dimensões da sustentabilidade empresarial nos relatórios de 2007, 2008 e 2009 das empresas pesquisadas.

Tabela 1

Evidenciação sobre as dimensões da sustentabilidade empresarial nos relatórios de sustentabilidade - 2007/2008/2009

\begin{tabular}{|c|c|c|c|c|c|c|}
\hline \multirow{2}{*}{$\begin{array}{l}\text { Dimensão da } \\
\text { sustentabilidade } \\
\text { empresarial }\end{array}$} & \multicolumn{2}{|c|}{2007 (19 empresas) } & \multicolumn{2}{|c|}{2008 (24 empresas) } & \multicolumn{2}{|c|}{2009 (23 empresas) } \\
\hline & $\begin{array}{c}\mathrm{N}^{\circ} \text { de } \\
\text { sentenças }\end{array}$ & $\begin{array}{c}\text { Proporção } \\
\text { (\%) }\end{array}$ & $\begin{array}{c}\mathrm{N}^{\circ} \text { de } \\
\text { sentenças }\end{array}$ & $\begin{array}{l}\text { Proporção } \\
\text { (\%) }\end{array}$ & $\begin{array}{c}\mathrm{N}^{\circ} \text { de } \\
\text { sentenças }\end{array}$ & $\begin{array}{c}\text { Proporção } \\
\text { (\%) }\end{array}$ \\
\hline Econômica & 2.193 & 20,8 & 2.995 & 21,5 & 2.901 & 24,8 \\
\hline Social Interna & 2.530 & 23,9 & 3.452 & 24,7 & 2.863 & 24,4 \\
\hline Social Externa & 2.976 & 28,2 & 3.766 & 27,0 & 3.209 & 27,4 \\
\hline Ambiental & 2.867 & 27,1 & 3.744 & 26,8 & 2.744 & 23,4 \\
\hline Total & 10.566 & 100,0 & 13.957 & 100,0 & 11.717 & 100,0 \\
\hline Média por empresa & \multicolumn{2}{|c|}{556} & \multicolumn{2}{|c|}{581} & \multicolumn{2}{|c|}{509} \\
\hline
\end{tabular}

Fonte: Dados da pesquisa.

Nota-se que apesar de em 2008 e 2009 o número de sentenças sobre as dimensões da sustentabilidade haver aumentado 32,1\% e 10,9\%, respectivamente, em relação ao de 2007, na verdade o volume de 2009 significou um decréscimo de $16 \%$ em relação a 2008, de maneira que não se pode afirmar que houve evolução na quantidade informativa dos relatórios no triênio em análise (Tabela 1).

No que tange às dimensões da sustentabilidade empresarial, verifica-se que a social externa foi a mais evidenciada nos três períodos analisados, seguida pela ambiental em 2007 e 2008 e pela econômica em 2009. Considerada conjuntamente, a dimensão social (interna e externa) representa 52,1\%,51,7\% e 51,8\% da evidenciação sobre as dimensões da sustentabilidade empresarial em 2007, 2008 e 2009, respectivamente. A dimensão econômica é a menos expressiva nos dois primeiros anos de análise, revelando que o relatório de sustentabilidade foi utilizado essencialmente como instrumento de evidenciação de práticas de responsabilidade socioambiental.

A Figura 5 ilustra o comportamento da evidenciação sobre as dimensões da sustentabilidade empresarial nos relatórios de 2007, 2008 e 2009 das empresas pesquisadas. 


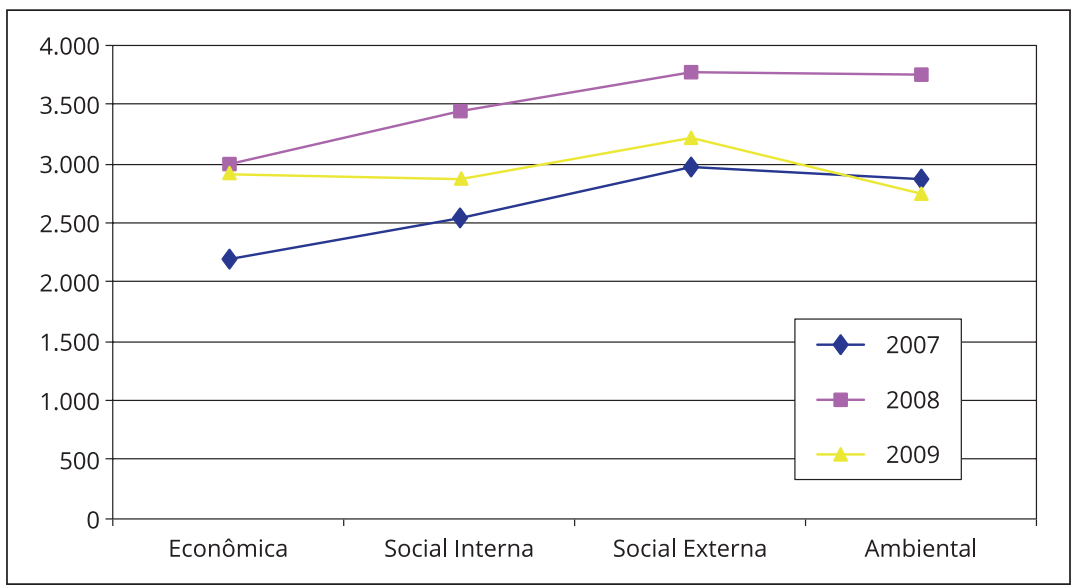

Figura 5. Comportamento da evidenciação sobre as dimensões da sustentabilidade nos relatórios de sustentabilidade

Fonte: Dados da pesquisa.

De acordo com a Figura 5, a dimensão ambiental foi a que apresentou a maior queda no número de sentenças evidenciadas nos relatórios de sustentabilidade das empresas, fato que influenciou o declínio da evidenciação geral das dimensões da sustentabilidade no documento ao longo do triênio analisado.

Em linhas gerais, os resultados desta pesquisa quanto à preponderância da dimensão social nos relatórios de sustentabilidade analisados corroboram os achados de Rezende, Junqueira e Medeiros (2008), que, ao analisar as práticas de responsabilidade social de empresas brasileiras premiadas no Guia Exame de Sustentabilidade de 2007, identificaram uma responsabilidade social orientada do âmbito interno para o externo.

A Tabela 2 demonstra a distribuição quantitativa de sentenças evidenciadas considerando o tipo de disclosure adotado sobre as dimensões da sustentabilidade empresarial nos relatórios de 2007, 2008 e 2009 das empresas pesquisadas.

Tabela 2

Distribuição quantitativa e proporcional das sentenças sobre as dimensões da sustentabilidade empresarial evidenciadas nos relatórios de sustentabilidade das empresas pesquisadas, por tipo de disclosure - 2007/2008/2009

\begin{tabular}{|c|c|c|c|c|c|c|}
\hline \multirow[b]{2}{*}{ Tipo de disclosure } & \multicolumn{2}{|c|}{2007 (19 empresas) } & \multicolumn{2}{|c|}{2008 (24 empresas) } & \multicolumn{2}{|c|}{2009 (23 empresas) } \\
\hline & $\begin{array}{c}\mathrm{N}^{\circ} \text { de } \\
\text { sentenças }\end{array}$ & $\begin{array}{l}\text { Proporção } \\
\text { (\%) }\end{array}$ & $\begin{array}{c}\mathrm{N}^{0} \text { de } \\
\text { sentenças }\end{array}$ & $\begin{array}{c}\text { Proporção } \\
\text { (\%) }\end{array}$ & $\begin{array}{c}\mathrm{N}^{\circ} \mathrm{de} \\
\text { sentenças }\end{array}$ & $\begin{array}{c}\text { Proporção } \\
\text { (\%) }\end{array}$ \\
\hline 1 & 4.205 & 39,8 & 5.353 & 38,3 & 4.339 & 37,0 \\
\hline 2 & 3.870 & 36,6 & 5.648 & 40,5 & 4.797 & 41,0 \\
\hline 3 & 2.491 & 23,6 & 2.956 & 21,2 & 2.581 & 22,0 \\
\hline Total & 10.566 & 100,0 & 13.957 & 100,0 & 11.717 & 100,0 \\
\hline Média por empresa & \multicolumn{2}{|c|}{556} & \multicolumn{2}{|c|}{581} & \multicolumn{2}{|c|}{509} \\
\hline
\end{tabular}

Fonte: Dados da pesquisa. 
Na Tabela 2, observa-se que em 2007 predominou o disclosure tipo 1 - evidenciação declarativa, enquanto em 2008 e 2009 predominou o tipo 2 - evidenciação quantitativa não-monetária. Nos três anos estudados, o disclosure tipo 3 - evidenciação quantitativa monetária foi o menos empregado. Considerada conjuntamente, a evidenciação quantitativa (monetária e não monetária) corresponde a 60,2\%, 61,7\% e $63 \%$ dos tipos de disclosure utilizados nos relatórios de sustentabilidade das empresas para evidenciação sobre as dimensões em 2007, 2008 e 2009, respectivamente, revelando um crescimento no volume de informações de natureza quantitativa no triênio.

A Figura 6 ilustra o comportamento dos três tipos de disclosure utilizados na evidenciação sobre as dimensões da sustentabilidade empresarial nos relatórios de 2007, 2008 e 2009 das empresas pesquisadas.

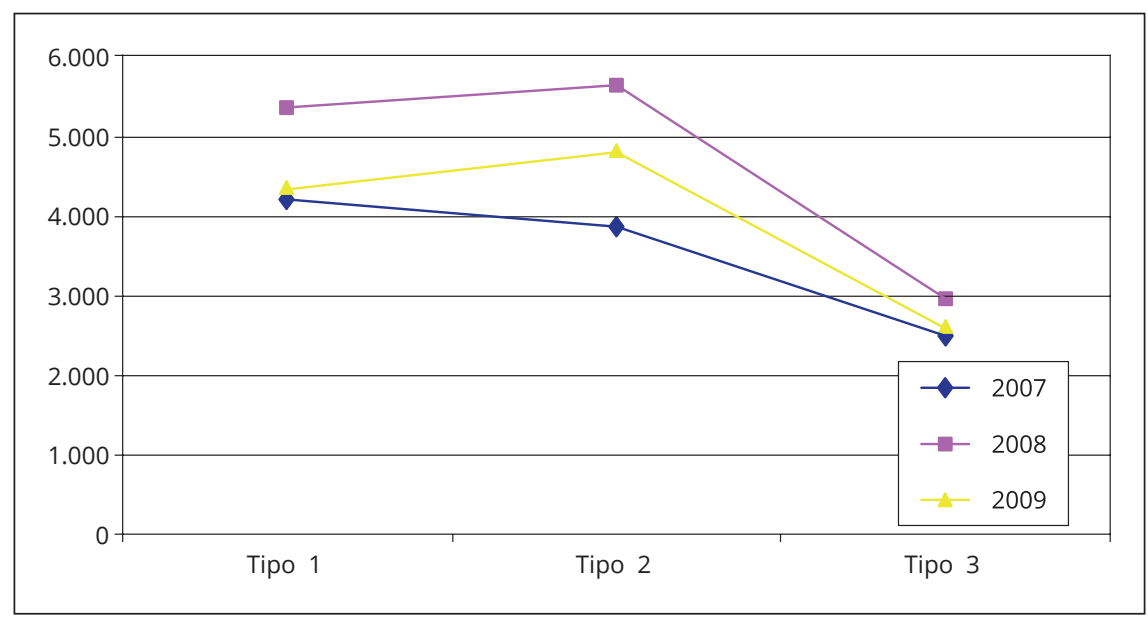

Figura 6. Comportamento dos tipos de disclosure adotados pelas empresas para evidenciação sobre as dimensões da sustentabilidade nos relatórios de sustentabilidade

Fonte: Dados da pesquisa.

Na Figura 6, observa-se que em 2009 o disclosure tipo 1 (evidenciação declarativa) registrou a maior queda no número de sentenças evidenciadas nos relatórios, em relação a 2008. Essa constatação corrobora os resultados obtidos por Kuasirikun e Sherer (2004), que destacam que a maioria das informações sobre o meio ambiente das empresas da Tailândia é divulgada de forma declarativa.

Verifica-se, ainda, que o disclosure tipo 3 (evidenciação quantitativa monetária) apresentou a menor representatividade e sofreu a menor oscilação no triênio analisado, divergindo dos achados de Moura, Nascimento e De Luca (2010), que, ao investigar a evidenciação voluntária de informações sociais de empresas das regiões Norte, Nordeste, Centro-Oeste e Sudeste listadas na BM\&FBovespa, segundo os indicadores do Guia da ONU, verificaram que os de caráter não financeiro foram os menos evidenciados.

A Tabela 3 apresenta a interseção dos dados das Tabelas 1 e 2, com vistas a apresentar o tipo de disclosure adotado para a evidenciação de sentenças relacionadas a cada uma das dimensões da sustentabilidade empresarial nos relatórios de 2007, 2008 e 2009 das empresas pesquisadas. 
Tabela 3

Dimensões da sustentabilidade empresarial, por tipo de disclosure - 2007/2008/2009

\begin{tabular}{|c|c|c|c|c|c|c|}
\hline \multicolumn{7}{|c|}{ Dimensão Econômica } \\
\hline \multirow[b]{2}{*}{ Tipo de disclosure } & \multicolumn{2}{|c|}{2007} & \multicolumn{2}{|c|}{2008} & \multicolumn{2}{|c|}{2009} \\
\hline & $\begin{array}{c}\mathrm{N}^{\circ} \text { de } \\
\text { sentenças }\end{array}$ & $\begin{array}{l}\text { Proporção } \\
\text { (\%) }\end{array}$ & $\begin{array}{c}\mathrm{N}^{0} \text { de } \\
\text { sentenças }\end{array}$ & $\begin{array}{c}\text { Proporção } \\
\text { (\%) }\end{array}$ & $\begin{array}{c}\mathrm{N}^{\circ} \text { de } \\
\text { sentenças }\end{array}$ & $\begin{array}{c}\text { Proporção } \\
\text { (\%) }\end{array}$ \\
\hline 1 & 770 & 35,1 & 940 & 31,4 & 890 & 30,7 \\
\hline 2 & 805 & 36,7 & 1.217 & 40,6 & 1.073 & 37,0 \\
\hline 3 & 618 & 28,2 & 838 & 28,0 & 938 & 32,3 \\
\hline Total & 2.193 & 100,0 & 2.995 & 100,0 & 2.901 & 100,0 \\
\hline \multicolumn{7}{|c|}{ Dimensão Social Interna } \\
\hline \multirow[b]{2}{*}{ Tipo de disclosure } & \multicolumn{2}{|c|}{2007} & \multicolumn{2}{|c|}{2008} & \multicolumn{2}{|c|}{2009} \\
\hline & $\begin{array}{c}\mathrm{N}^{\circ} \text { de } \\
\text { sentenças }\end{array}$ & $\begin{array}{l}\text { Proporção } \\
(\%)\end{array}$ & $\begin{array}{c}\mathrm{N}^{0} \text { de } \\
\text { sentenças }\end{array}$ & $\begin{array}{c}\text { Proporção } \\
\text { (\%) }\end{array}$ & $\begin{array}{c}\mathrm{N}^{\circ} \text { de } \\
\text { sentenças }\end{array}$ & $\begin{array}{c}\text { Proporção } \\
\text { (\%) }\end{array}$ \\
\hline 1 & 1.059 & 41,9 & 1.493 & 43,3 & 1.061 & 37,1 \\
\hline 2 & 950 & 37,5 & 1.385 & 40,1 & 1.091 & 38,1 \\
\hline 3 & 521 & 20,6 & 574 & 16,6 & 711 & 24,8 \\
\hline Total & 2.530 & 100,0 & 3.452 & 100,0 & 2.863 & 100,0 \\
\hline \multicolumn{7}{|c|}{ Dimensão Social Externa } \\
\hline \multirow[b]{2}{*}{ Tipo de disclosure } & \multicolumn{2}{|c|}{2007} & \multicolumn{2}{|c|}{2008} & \multicolumn{2}{|c|}{2009} \\
\hline & $\begin{array}{c}\mathrm{N}^{\circ} \text { de } \\
\text { sentenças }\end{array}$ & $\begin{array}{l}\text { Proporção } \\
\text { (\%) }\end{array}$ & $\begin{array}{c}\mathrm{N}^{0} \text { de } \\
\text { sentenças }\end{array}$ & $\begin{array}{l}\text { Proporção } \\
\text { (\%) }\end{array}$ & $\begin{array}{c}\mathrm{N}^{\circ} \text { de } \\
\text { sentenças }\end{array}$ & $\begin{array}{c}\text { Proporção } \\
(\%)\end{array}$ \\
\hline 1 & 1.260 & 42,3 & 1.393 & 37,0 & 1.262 & 39,3 \\
\hline 2 & 1.005 & 33,8 & 1.460 & 38,8 & 1.430 & 44,6 \\
\hline 3 & 711 & 23,9 & 913 & 24,2 & 517 & 16,1 \\
\hline Total & 2.976 & 100,0 & 3.766 & 100,0 & 3.209 & 100,0 \\
\hline \multicolumn{7}{|c|}{ Dimensão Ambiental } \\
\hline \multirow[b]{2}{*}{ Tipo de disclosure } & \multicolumn{2}{|c|}{2007} & \multicolumn{2}{|c|}{2008} & \multicolumn{2}{|c|}{2009} \\
\hline & $\begin{array}{c}\mathrm{N}^{\circ} \text { de } \\
\text { sentenças }\end{array}$ & $\begin{array}{l}\text { Proporção } \\
\text { (\%) }\end{array}$ & $\begin{array}{c}\mathrm{N}^{\circ} \text { de } \\
\text { sentenças }\end{array}$ & $\begin{array}{l}\text { Proporção } \\
\text { (\%) }\end{array}$ & $\begin{array}{c}\mathrm{N}^{\circ} \text { de } \\
\text { sentenças }\end{array}$ & $\begin{array}{c}\text { Proporção } \\
\text { (\%) }\end{array}$ \\
\hline 1 & 1.116 & 38,9 & 1.433 & 38,3 & 1.126 & 41,0 \\
\hline 2 & 1.110 & 38,7 & 1.636 & 43,7 & & 43,9 \\
\hline 3 & 641 & 22,4 & 675 & 18,0 & 415 & 15,1 \\
\hline Total & 2.867 & 100,0 & 3.744 & 100,0 & 2.744 & 100,0 \\
\hline
\end{tabular}

Fonte: Dados da pesquisa.

Na Tabela 3, nota-se que, para a evidenciação de informações relacionadas à dimensão econômica, as empresas adotaram prioritariamente o disclosure tipo 2 (evidenciação quantitativa não-monetária). $\mathrm{O}$ mesmo acontece com as dimensões social externa e ambiental nos anos 2008 e 2009. Por sua vez, para a dimensão social interna há preponderância de informações do disclosure tipo 1 (evidenciação declarativa), corroborando os resultados obtidos por Gallon e Ensslin (2008).

Observa-se ainda que das quatro dimensões analisadas, as informações sobre a dimensão econômica foram as mais mensuradas e as informações sobre a dimensão ambiental as menos mensuradas em termos de valores monetários, o que pode indicar a dificuldade das empresas em relação ao reconhecimento e mensuração de ativos, passivos, custos e despesas ambientais. Esses resultados refutam os achados de Clarkson et al. (2007), que ao revisar a relação entre evidenciação e performance ambiental em em- 
presas norte-americanas de setores poluentes constataram a existência de uma associação positiva entre performance ambiental e o nível de evidenciação ambiental discricionária. Divergem também dos resultados de Al-Tuwaijri,Christensen e Hughes II (2004) que apontam que uma boa performance ambiental é associada com uma evidenciação ambiental mais extensiva quantitativamente de medidas e ocorrências específicas de poluição.

A partir da identificação de que a dimensão social externa é a mais evidenciada nos três anos pelas empresas premiadas seria importante relacionar essa constatação com outras variáveis que possam justificar esse resultado, observando pressupostos e técnicas estatísticas (aspecto não investigado nessa pesquisa puramente qualitativa).

\subsection{Identificação de possíveis fatores indicativos dos níveis de evidenciação sobre as dimensões da sustentabilidade nos relatórios das empresas pesquisadas}

Cabe esclarecer que para a consecução do segundo objetivo específico da pesquisa - identificar possíveis fatores indicativos dos níveis de evidenciação sobre as dimensões da sustentabilidade nos relatórios das empresas pesquisadas -, a análise considerou a evidenciação nos relatórios de sustentabilidade de 2009. Dessa forma, participaram da análise as 23 empresas que elaboraram e disponibilizaram seus relatórios de sustentabilidade referentes ao exercício de 2009 nos respectivos portais eletrônicos.

Para a análise foram considerados os seguintes possíveis fatores indicativos: setor de atividade, efeito da atividade no meio ambiente, porte, estrutura de propriedade do capital e segmento de listagem da BM\&FBovespa. A opção por esses fatores deve-se ao fato de terem sido também considerados em outros estudos sobre a temática da evidenciação voluntária, como em Cunha e Ribeiro (2008).

A Tabela 4 apresenta a distribuição quantitativa de sentenças evidenciadas sobre as dimensões da sustentabilidade empresarial, estratificada entre os possíveis fatores indicativos dos níveis de evidenciação nos relatórios de 2009.

Tabela 4

Possíveis fatores indicativos dos níveis de evidenciação em 2009

\begin{tabular}{|c|c|c|c|c|c|c|c|}
\hline \multirow[t]{2}{*}{ Fator } & \multirow{2}{*}{$\begin{array}{c}N^{\circ} \text { de } \\
\text { empresas }\end{array}$} & \multicolumn{6}{|c|}{$\begin{array}{l}\text { Quantidades de sentenças evidenciadas sobre as dimensões } \\
\text { da sustentabilidade das empresas pesquisadas por } \\
\text { fator, dimensão, total e média por empresa }\end{array}$} \\
\hline & & Econômica & $\begin{array}{c}\text { Social } \\
\text { Interna }\end{array}$ & $\begin{array}{c}\text { Social } \\
\text { Externa }\end{array}$ & Ambiental & Total & $\begin{array}{c}\text { Média por } \\
\text { Empresa }\end{array}$ \\
\hline \multicolumn{8}{|l|}{ Setor de atividade } \\
\hline Bens de consumo & 3 & 300 & 549 & 613 & 481 & 1.943 & 647,7 \\
\hline Eletroeletrônico & 1 & 94 & 118 & 124 & 97 & 433 & 433 \\
\hline Energia & 5 & 785 & 803 & 742 & 811 & 3.141 & 628,2 \\
\hline Finanças & 3 & 858 & 398 & 457 & 284 & 1.997 & 665,7 \\
\hline Indústria da construção & 1 & 42 & 87 & 82 & 90 & 301 & 301 \\
\hline Informática & 1 & 9 & 35 & 145 & 52 & 241 & 241 \\
\hline Madeira & 1 & 92 & 103 & 127 & 133 & 455 & 455 \\
\hline Mineração & 1 & 87 & 49 & 66 & 105 & 307 & 307 \\
\hline Papel e celulose & 2 & 272 & 341 & 333 & 303 & 1.249 & 624,2 \\
\hline Seguros e previdência & 1 & 118 & 55 & 39 & 8 & 220 & 220 \\
\hline Serviços & 2 & 190 & 235 & 288 & 191 & 904 & 452 \\
\hline Siderurgia e metalurgia & 1 & 34 & 32 & 69 & 68 & 203 & 203 \\
\hline Comércio varejista & 1 & 20 & 58 & 124 & 121 & 323 & 323 \\
\hline
\end{tabular}




\begin{tabular}{|c|c|c|c|c|c|c|c|}
\hline \multirow[t]{2}{*}{ Fator } & \multirow{2}{*}{$\begin{array}{c}N^{\circ} \text { de } \\
\text { empresas }\end{array}$} & \multicolumn{6}{|c|}{$\begin{array}{l}\text { Quantidades de sentenças evidenciadas sobre as dimensões } \\
\text { da sustentabilidade das empresas pesquisadas por } \\
\text { fator, dimensão, total e média por empresa }\end{array}$} \\
\hline & & Econômica & $\begin{array}{c}\text { Social } \\
\text { Interna }\end{array}$ & $\begin{array}{c}\text { Social } \\
\text { Externa }\end{array}$ & Ambiental & Total & $\begin{array}{l}\text { Média por } \\
\text { Empresa }\end{array}$ \\
\hline \multicolumn{8}{|c|}{$\begin{array}{l}\text { Efeito da atividade } \\
\text { no meio ambiente }\end{array}$} \\
\hline Poluente & 15 & 1.706 & 2.082 & 2.156 & 2.088 & 8.032 & 535,5 \\
\hline Não poluente & 8 & 1.195 & 781 & 1.053 & 656 & 3.685 & 460,6 \\
\hline \multicolumn{8}{|l|}{ Porte } \\
\hline Grande & 22 & 2.783 & 2.808 & 3.170 & 2.736 & 11.497 & 522,6 \\
\hline Médio & 1 & 118 & 55 & 39 & 8 & 220 & 220 \\
\hline \multicolumn{8}{|c|}{$\begin{array}{l}\text { Estrutura de } \\
\text { propriedade do capital }\end{array}$} \\
\hline Aberto & 11 & 2.002 & 1.770 & 1.849 & 1.538 & 7.159 & 650,8 \\
\hline Fechado & 12 & 899 & 1093 & 1360 & 1.206 & 4.558 & 379,8 \\
\hline \multicolumn{8}{|c|}{ Segmento de listagem } \\
\hline -Tradicional & 2 & 316 & 339 & 335 & 254 & 1.244 & 622 \\
\hline Nível 1 & 3 & 385 & 454 & 524 & 413 & 1.776 & 592 \\
\hline Nível 2 & 1 & 598 & 130 & 110 & 30 & 868 & 868 \\
\hline Novo Mercado & 5 & 703 & 847 & 880 & 841 & 3.271 & 654,2 \\
\hline
\end{tabular}

Inicialmente, cabe enfatizar que algumas análises sobre os possíveis fatores indicativos dos níveis de evidenciação nos relatórios de sustentabilidade de 2009 ficaram comprometidas, devido à concentração de algumas empresas em determinadas categorias, como porte (concentração de empresas de grande porte), a pulverização das 23 empresas em 13 setores de atividade e o reduzido número de empresas participantes dos segmentos de listagem da BM\&FBovespa (11). Contudo, independentemente das limitações da análise, os principais resultados elucidados na Tabela 4 são comentados a seguir.

$\mathrm{Na}$ comparação por setor de atividade, as empresas dos setores finanças, bens de consumo, energia e papel e celulose são as que apresentam os maiores níveis de evidenciação, enquanto as dos setores siderurgia e metalurgia, seguros e previdência e informática apresentam os menores níveis. Em alguns setores observa-se a preponderância de informações relacionadas a algumas dimensões da sustentabilidade empresarial, como em energia, mineração e comércio varejista no tocante à dimensão ambiental, e nos setores bens de consumo, energia, informática, papel e celulose, serviços e comércio varejista com relação à dimensão social externa.

No que tange ao efeito da atividade no meio ambiente, observa-se que os relatórios de sustentabilidade de 2009 das empresas consideradas poluentes apresentam mais sentenças e priorizaram a evidenciação de informações relacionadas às dimensões social externa e ambiental, diferentemente das empresas caracterizadas como não poluentes, que apresentam nível mais baixo de evidenciação e evidenciaram mais informações da dimensão econômica, apontando o efeito da atividade no meio ambiente como fator indicativo do nível e do foco da evidenciação das dimensões da sustentabilidade nos seus relatórios.

Em relação ao porte das empresas, apesar de quase todas (21) serem de grande porte, é possível observar que apresentaram maior nível de evidenciação médio do que as de médio porte.

Fato interessante diz respeito à análise da evidenciação quanto à estrutura de propriedade do capital das empresas, haja vista que as de capital aberto apresentam nível de evidenciação bastante superior em relação às de capital fechado, sugerindo a estrutura de propriedade do capital como fator indicativo do nível de evidenciação das dimensões da sustentabilidade nos relatórios das empresas. Lins e Silva (2009) discorrem sobre a importância da divulgação de informações socioambientais como forma de atrair investidores, já que o disclosure desempenha papel essencial na redução da assimetria informacional entre os gestores e aqueles que têm interesse na empresa. 
Apesar das limitações da análise por segmento de listagem, já que apenas 11 das empresas pesquisadas são listadas na BM\&FBovespa, não se pode inferir que há correspondência evidente entre o respectivo segmento de listagem e o nível de evidenciação de informações sobre as dimensões da sustentabilidade empresarial nos relatórios de cada empresa. Os resultados demonstram que: (i) as empresas que, mesmo com ações negociadas na BM\&FBovespa, não participam de nenhum dos três níveis diferenciados de governança corporativa, apresentam número médio de sentenças evidenciadas superior ao das empresas do Nível 1; e (ii) as empresas do Nível 2 apresentam número médio de sentenças evidenciadas superior ao das empresas do Novo Mercado. Essas constatações contrariam a afirmação da BM\&FBovespa (2011) de que as empresas listadas nesses três segmentos especiais oferecem melhores práticas de governança corporativa, ampliando os direitos dos acionistas minoritários, e aumentam a transparência das companhias, com divulgação de maior volume de informações e de mais qualidade, facilitando o acompanhamento de sua performance. Os resultados refutam o estudo de Cunha e Ribeiro (2008), que ao investigar os incentivos das companhias com ações negociadas no mercado de capitais brasileiro para divulgação voluntária de informações de natureza social, concluiu que essa espontaneidade está associada positivamente ao nível de governança corporativa.

Nesse ponto da pesquisa cabe elucidar que os resultados preliminares obtidos a partir da análise qualitativa do conteúdo dos relatórios de sustentabilidade das empresas premiadas devem ser examinados também por meio da aplicação de algumas técnicas multivariadas capazes de confirmar a relação entre variáveis.

\section{Conclusão}

A pesquisa teve como principal objetivo analisar o conteúdo da divulgação de informações acerca das dimensões da sustentabilidade empresarial - econômica, social e ambiental - nos relatórios de sustentabilidade de empresas premiadas por suas práticas de responsabilidade socioambiental. A análise de conteúdo dos relatórios de sustentabilidade das empresas (2007, 2008 e 2009) considerou as sentenças como unidades de análise e contemplou dois campos de observação: as dimensões da sustentabilidade empresarial e os tipos de disclosure adotados.

De acordo com os resultados obtidos, as empresas participantes da pesquisa - premiadas pelo Guia Exame de Sustentabilidade (2009) e vencedoras do Prêmio ECO, da AMCHAM e do Valor Econômico (2007, 2008 ou 2009) - são, em sua maioria, de grande porte, possuem capital fechado, atuam nos setores de energia, finanças e bens de consumo e suas atividades se caracterizam como poluente, de acordo com o Anexo VIII da Lei no 10.165/2000, que trata da Política Nacional do Meio Ambiente.

Através da análise qualitativa dos relatórios, com relação ao nível de evidenciação sobre as dimensões da sustentabilidade e aos tipos de disclosure adotados pelas empresas pesquisadas, não se pode afirmar que houve uma evolução na quantidade informativa dos relatórios no triênio em análise. Em linhas gerais, foi possível observar que a dimensão social externa foi a mais evidenciada nos três períodos analisados, seguida em 2007 e 2008 pela dimensão ambiental. A dimensão econômica foi a menos expressiva nos dois primeiros anos analisados, revelando que o relatório de sustentabilidade foi utilizado pelas empresas essencialmente como instrumento de evidenciação de suas práticas de responsabilidade socioambiental. Quanto aos tipos de disclosure, verificou-se que em 2007 o tipo 1 - evidenciação declarativa preponderou, enquanto em 2008 e 2009 predominou o tipo 2 - evidenciação quantitativa não-monetária. Observou-se que nos três anos estudados o disclosure do tipo 3 - evidenciação quantitativa monetária foi o menos empregado.

No que tange à identificação de possíveis fatores indicativos dos níveis de evidenciação sobre as dimensões da sustentabilidade nos relatórios das empresas pesquisadas, apesar das limitações da análise, constatou-se que: (i) as empresas dos setores finanças, bens de consumo, energia e papel e celulose apresentaram os mais elevados níveis de evidenciação, enquanto as dos setores siderurgia e metalurgia, segu- 
ros e previdência e informática apresentaram os menores níveis; (ii) os fatores efeito da atividade no meio ambiente e estrutura de propriedade do capital foram apontados como indicativos dos níveis de informações sobre as dimensões da sustentabilidade empresarial nos relatórios das empresas; (iii) não há correspondência evidente entre o segmentos de listagem das empresas na BM\&FBovespa e os níveis de evidenciação de informações sobre as dimensões da sustentabilidade nos respectivos relatórios.

Por fim, vale lembrar que a análise qualitativa realizada, ainda que embrionária, sinalizou importantes pontos sobre a evidenciação voluntária das dimensões da sustentabilidade corporativa nos relatórios de empresas premiadas por suas práticas de responsabilidade socioambiental. Entretanto, reitera-se a necessidade de complementação dos mesmos por meio da aplicação em pesquisas futuras de análises estatísticas, com o intuito de confirmar possíveis relações entre variáveis, bem como fazer análises estatísticas para verificar diferenças entre: (i) o grupo de empresas de capital fechado e de capital aberto, e (ii) o grupo de empresas que não receberam prêmios com aquelas que receberam, com o intuito de confirmar se as empresas que receberam prêmio podem ser consideradas referenciais (benchmark) em termos de evidenciação para outras empresas que não fazem parte desse universo e que buscam o reconhecimento da sociedade como forma de alcançar a legitimidade.

Especificamente sobre a identificação do maior nível de evidenciação dos fatores setor de atividade, efeito da atividade no meio ambiente e estrutura de propriedade do capital, cabe elucidar que, apesar do rigor científico aplicado, é importante que em estudos futuros sejam empregadas técnicas estatísticas multivariadas como a Análise de Correspondência (Anacor) e a Análise Discriminante, para se poder discernir não somente sobre fatores indicativos, mas também sobre fatores explicativos ou condicionantes dos níveis de evidenciação voluntária de informações socioambientais nas empresas brasileiras.

\section{Referências}

Adams, C. A., Hill, W-Y.; Roberts, C. B. (1998). Corporate social reporting practices in Western Europe: legitimating corporate behavior? British Accounting Review, (30)1, 1-21.

Adams, C. A. (2004). The ethical, social and environmental reporting-performance portrayal gap. Accounting, Auditing \& Accountability Journal, 17(5), 731-757.

Aerts, W. \& Cormier, D. (2009). Media legitimacy and corporate environmental communication. Accounting, Organizations and Society, 34(1), 1-27.

Almeida, F. (2002). O bom negócio da sustentabilidade. Rio de Janeiro: Nova Fronteira.

Al-Tuwaijri, S.A., Christensen, T. E. \& Hughes II, K. E. (2004). The relations among environmental disclosure, environmental performance, and economic performance: a simultaneous equations approach. Accounting, Organization and Society, 29(5-6), 447-471.

Anderson, J. C. \& Frankle, A. W. (July 1980). Voluntary social reporting: an iso-beta portfolio analysis. The Accounting Review, 55(3), 467-479.

Bardin, L. (2004). Análise de conteúdo. Lisboa: Edições 70.

Becchetti, L., Di Giacomo, S. \& Pinnacchio, D. (2005). Corporate social responsibility and corporate performance: evidence from a panel of US listed companies. Research Paper Series, 26(78), 1-56.

BM\&FBOVESPA. Segmentos de listagem. Recuperado em 20 janeiro, $2011 \mathrm{de}<\mathrm{http}$ ://www.bmfbovespa. com.br/empresas/pages/empresas_segmentos-de-listagem.asp $>$.

Lei $n^{\circ} 10.165$, de 27 de dezembro de 2000. Altera a Lei no 6.938, de 31 de agosto de 1981, que dispõe sobre a Política Nacional do Meio Ambiente, seus fins e mecanismos de formulação e aplicação, e dá outras providências. Diário Oficial da União. Brasília-DF. Recuperado em: 20 jan., 2011 de <http:// www.planalto.gov.br/ccivil_03/Leis/L10165.htm>. 
Lei $n^{\circ} 11.638$, de 28 de dezembro de 2007. Altera e revoga dispositivos da Lei no 6.404, de 15 de dezembro de 1976, e da Lei no 6.385, de 7 de dezembro de 1976, e estende às sociedades de grande porte disposições relativas à elaboração e divulgação de demonstrações financeiras. Diário Oficial da União. Brasília-DF. Recuperado em 6 fev., 2011 de <http://www.planalto.gov.br/ccivil_03/_ato20072010/2007/Lei/L11638.htm>.

Brown, N \& Deegan, C. (1998). The public disclosure of environmental performance information - a dual test of media agenda setting theory and legitimacy theory. Accounting and Business Research, 29(1), 21-41.

Branco, M. C.; Eugênio, T. \& Ribeiro, J. (2008). Environmental disclosure in response to public perception of environmental threats: the case of co-incineration in Portugal. Journal of Communication Management, 12(2), 136-151.

Cho, C. H. \& Patten, D. M. (2007). The role of environmental disclosures as tools of legitimacy: A research note. Accounting, Organization and Society, 32(7-8), 639-647.

Clarkson, G; Jacobsen, T. E. \& Batcheller, A. L. (2007). Information asymmetry and information sharing. Government Information Quarterly, 24, 827-839.

Cunha, J. V. A. da \& Ribeiro, M. S. (2008). Divulgação voluntária de informações de natureza social: um estudo nas empresas brasileiras. Revista de Administração Eletrônica - RAUSP, 1(1), 1-23.

Deegan, C. (2002). The legitimising effect of social and environmental disclosures - a theoretical foundation. Accounting, Auditing and Accountability Journal, 15(3), 282-311.

Deegan, C.; Rankin, M. \& Tobin, J. (2002). An examination of the corporate social and environmental disclosures of BHP from 1983-1997: a test of legitimacy theory. Accounting, Auditing e Accountability Journal, 15(3), 312-343.

Deegan, C. Legitimacy theory. In: Hoque, Z. (2005) Methodological issues in accounting research: theories and methods. Londres: Spiramus, pp. 161-179.

Delai, I. \& Takahashi, S. (2008). Uma proposta de modelo de referência para mensuração da sustentabilidade corporativa. Revista de Gestão Social e Ambiental, 2(1), 19-40.

Ferreira, A. C.S. (2011). Contabilidade ambiental: uma informação para o desenvolvimento sustentável. (3ª. ed. ). São Paulo: Atlas.

Gallon, A. V. \& Ensslin, S. R. (2008). Evidenciação estratégica dos pilares da sustentabilidade empresarial: investigação no relatório da administração das empresas que compõem o ISE. Revista Pensar Contábil, 1(1), 5-14.

Gray, R. H. \& Bebbington, J. (2001). Accounting for the environment. (2. ed.). Londres: Sage.

Gray, R., Kouhy, R. \& Lavers, S. (1995). Corporate social and environmental reporting: a review of the literature and a longitudinal study of UK disclosure. Accounting, Auditing and Accountability Journal, 8(2), 47-77.

Guthrie, J. \& Parker, L. D. (1989). Corporate social reporting: a rebuttal of legitimacy theory. Accounting and Business Research, 19(76), 343-352.

GRI (Global Reporting Initiative). (2009). Conjunto de protocolos de indicadores. Recuperado em 11 set., 2012 de <http://www.globalreporting.org $>$..

Kuuasirikun, N. \& Sherer, M. (2004) .Corporate social accounting disclosure in Thailand. Accounting, Auditing \& Accountability Journal, 17(4), 629-660..

Lins, L. S. \& Silva, R. N. S. (2009). Responsabilidade sócio-ambiental ou Greenwash: uma avaliação com base nos relatórios de sustentabilidade ambiental. Sociedade, Contabilidade e Gestão, 4(1), 91-105. 
Mattila, M.. (2009). Corporate social responsibility and image in organizations: for the insiders or the outsiders? Social Responsibility Journal, 5(4), 540-549.

Milani Filho, M. A. F. (2008). Responsabilidade social e investimento social privado: entre o discurso e a evidenciação. Revista Contabilidade \& Finanças, 19(47), 89-101.

Moura, A. A. F. de, Nascimento, F. S. P. do \& De Luca, M. M. M.. (2010), Evidenciação voluntária de informações sociais por empresas de capital aberto sediadas nas regiões Norte, Nordeste, Centro-Oeste e Sudeste do Brasil: um estudo com base nos indicadores de responsabilidade social corporativa da ONU. Anais do Congresso Brasileiro de Custos, Belo Horizonte, MG, Brasil, 17.

Nascimento, A. R. do, Santos, A. dos, Salotti, B. \& Múrcia, F. Dal-Ri. (2009). Disclosure social e ambiental: análises das pesquisas científicas veiculadas em periódicos de língua inglesa. Revista Contabilidade Vista \& Revista, 20(1), 15-40.

Nossa, V. (2002). Disclosure ambiental: uma análise do conteúdo dos relatórios ambientais de empresas do setor de papel e celulose em nível internacional. 2002. $246 \mathrm{f}$. Tese (Doutorado em Controladoria e Contabilidade) Universidade de São Paulo, São Paulo, Brasil.

Prescott-Allen, R. (1997). Barometer of sustainability. In: Moldan, Bedrich; Bilharz, Suzanne. (1997) Sustainability indicators: report of the project on indicators of sustainable development. Chicester: John Wiley \& Sons Ltd.

Rezende, J. M., Junqueira, M. C. \& Medeiros, C. R. de O. (2008). Responsabilidade social empresarial: uma prática de gestão? Anais da Semana do Servidor e Semana Acadêmica,.., Uberlândia, MG, Brasil, 4.

Ribeiro, A. M. \& Van Bellen, H. M. (2008). Evidenciação ambiental: uma comparação do nível de evidenciação entre os relatórios de empresas brasileiras. Anais do Congresso USP de Controladoria e Contabilidade, São Paulo. Brasil, 8.

Rover, S. \& Murcia, F. Dal-Ri. (2010). Influência do disclosure voluntário econômico e socioambiental no custo de capital próprio de empresas brasileiras. Anais do Congresso ANPCONT, Natal, RN, Brasil, 4.

Suchman, M. C. (1995).Managing legitimacy: strategic and institutional approaches. Academy of Management Review, 20(3), 571-610.

Teixeira, E. A. \& Nossa, V. (2010). Sinalizando responsabilidade social: relação entre o índice de sustentabilidade empresarial e a estrutura de capital das empresas. Anais do Congresso ANPCONT, Natal, RN, Brasil, 4.

Vanstraelen, A., Zazerski, M. T. \& Robb, S. W. G. (2003). Corporate nonfinancial disclosure practices and financial analyst forecast ability across three European countries. Journal of International Financial Management and Accounting, 14(3), 249-278. DOI: 10.1111/1467-646X.00098

Vellani, C. L. \& Ribeiro, M. S. (2009). Sustentabilidade e contabilidade. Revista Contemporânea de Contabilidade, 6(11), 187-206

Voss, B. L., Pfitscher, E. D. \& Cruz, F. da. (2010). Responsabilidade social das entidades premiadas pela ADVB/SC do ano de 2006. Anais do Simpósio de Administração da Produção, Loogística e Operações Internacionais - SIMPOI, São Paulo, Brasil, 13.

Wang, L. (2005). A methodology of sustainability accountability and management for industrial enterprises. Doctoral Dissertation, Faculty of Graduate School. The State University of New York at Buffalo, Buffalo, USA. 